\title{
The Labors of Hercules and Sisyphus
}

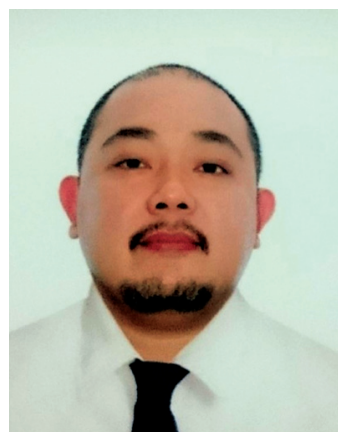

There are times when one thinks a task too great or too burdensome, requiring immense effort.

I imagine that this must be the feeling of a researcher, who, after exhaustive journal searches, laboratory experiments, and data gathering, is finally, finally getting down to writing his or her manuscript. A product of so many months, or years, there always is that struggle to get the first paragraph going and from there, the second, the third, and so on.

Why did we do the study in the first place, the background and rationale of it all, the related literature and research objectives, these sometimes become difficult to pin down on the blank page. How did we perform the research, what did we exactly do, the methods section teeters between too much and too little information, a delicate balance that needs to be achieved to achieve replicability, repeatability.

Can our results withstand scrutiny, the data are there, analyzed, waiting to be integrated into the body of the paper, transformed into figures and tables, diagrams and appendices. Then there are the references, the care that comes into making sure that these are cross linked properly, in ascending order, expressed in the appropriate, at times challenging, but required citation formats. All this, in a word, can only best be described as Herculean.

At the other end, lies the arduous task of the editor and the publisher, mirroring, in many respects, the labors of the manuscript writer and researcher. Sisphyean, this time, as another aspect, perhaps unrealized by many, emerges - the cyclical pattern of effort upon editorial effort, of inviting and soliciting articles, engaging reviewers and retaining them, processing and polishing manuscripts, to beat the publication cycle and still meet standards, each issue a display of consistency, a faithful replication.

Like a colossal rock being rolled slowly up a hill, the labors of publication increase as one reaches the apex: once completed at the top, one witnesses everything reset, rolling down, back to the starting point, with each new volume and issue. It never ends.

Time is not helping at all. There are so many other things to do, slides to read, results to release, laboratories to visit, meetings to attend, a million more things that remunerate much more than this academic exercise. Deadlines are stressful, and if we learned anything at all in our lifetimes, it is to mitigate or eliminate the source of the stress.

I write this right at the cusp of a new issue, our first issue for 2018. Articles have slowly trickled in. Some made it on time, others needing a bit more to pass the bar. Another lean harvest in numbers, but bountiful in new learning and knowledge for pathologists of every generation.

Like Hercules, like Sisyphus, we, researchers and editors, must go on.

For our research needs to be written up and submitted, our output published, built upon and translated to new knowledge, transformed to policy. In the end, this is our obligation as scientists to our people, to humanity even. And there are miles to go before we all get to sleep.

\section{Amado O. Tandoc III, MD, FPSP}

Editor-in-Chief 